\title{
Lo Tradicional Cubano en el Mundo Novelístico de José Lezama Lima
}

Con Paradiso sucede lo que a menudo ocurre con algunas obras clásicas: son muchos los que las elogian, pocos los que las leen enteramente y escasísimos los que logran adentrarse en su intimidad. La novela de Lezama Lima tiene la agravante de que su extraordinaria riqueza alusiva y la vertiginosa proliferación de sus imágenes exigen que el lector se mantenga constantemente alerta al reto que el autor le lanza en cada página. Aún así, en las ágiles jugadas de ese ajedrez mental no es infrecuente que sea el lector quien pierda la partida. Paradiso constituye, en cierto modo, una summa de tradiciones y de perspectivas ante las cuales se ha de mantener un tesonero asedio. En esta ocasión iniciaré el asedio situándome en la obligada vía de acceso al centro de la obra: lo tradicional cubano, lo raigal e inmanente en ese mundo de sensaciones, de recuerdos y de lecturas familiares que conforman y determinan la cosmovisión del novelista.

Comenzaré por lo más saliente: el nombre del protagonista y el título de la obra. La extrañeza de uno y otro ha despistado a algunos criticos a quienes de ese modo se le han escapado las claves míticas que subyacen en ambos. José Cemí lleva, en efecto, un apellido inusitado. Cemi es una palabra que debiera de haberse registrado desde hace tiempo en el Diccionario de la lengua española, pero precisamente es otra de las voces, de hondo arraigo antillano, que allí brillan por su ausencia. Tal ausencia, en ése y otros diccionarios, ha dado lugar a que se hayan propuesto diversas interpretaciones de su significado. Un destacado crítico sudamericano piensa que tal vez sea "una voluntaria anagramatización onomástica: Lezama Lima / ez-im / ce-mí'. Una profesora inglesa, de brillante ejecutoria hispanoamericanista, comenta que "el nombre deriva de sema o signo". 2 Otro crítico, aturdido acaso por los estruendosos tambores de la música afrocubana, opina que Cemí es "un vasco con nombre yoruba". 3 Y a numerosas personas les he oído decir

\footnotetext{
1 Haroldo de Campos, "Superación de los lenguajes exclusivos" , América Latina en su literatura, México, Siglo XXI Editores, 1972, pág. 291.

2 Jean Franco, "Lezama Lima en el paraíso de la poesía", Vórtice, Stanford, California, I. núm. 1, Primavera 1974 , pág. 32.

3 Mario Trajtenberg, "De Narciso a Fronesis: la condición del poeta', Arbol de Letras, Santiago de Chile, vol. 2,11 , Julio de 1969 , pág. 16, col. 2 .
} 
que las iniciales de José Cemí aluden, desde luego, a Jesucristo. Esos comentarios sin duda aumentan los planos polisémicos que el lector tiene derecho a convocar. Pero creo que también debiera de tenerse en cuenta el sentido original del término. Porque cemíno es un nombre de origen yoruba. Ni tampoco se deriva del griego. Es voz taína. Y como la lengua taína sigue todavía mal descrita en el Diccionario de la Real Academia, ${ }^{4}$ perdonen los enterados que me vea en la obligación de explicar que aquella lengua era la que más extensamente hablaban los aborígenes antillanos a la llegada de Colón. Y ya en plan de explicaciones, debo insistir en que, contrario a lo que se ha venido repitiendo desde hace siglos, los taínos no fueron exterminados en los primeros choques de la conquista. Es cierto que fueron diezmados por los desafueros de la turba conquistadora, por las enfermedades que introdujeron los recién llegados y por el cruel tratamiento a que fueron sometidos los que cayeron en manos de los encomenderos. Pero no todos los españoles fueron crueles, ni todos los taínos fueron exterminados. Hubo también entre conquistadores y conquistados un paulatino proceso de convivencia y transculturación. Mediante ese proceso el pueblo taíno dio un considerable número de voces que han enriquecido tanto al español general como al particular de aquellas islas, legó hábitos y costumbres que aún se conservan en gran parte de la población, y dejó, como en el caso que aquí nos ocupa, el soterrado recuerdo de una mitologia que sorpresivamente aflora en determinadas creencias y creaciones artísticas de los antillanos de hoy. ${ }^{\mathbf{5}}$ Pues bien, en esa mitología cemí es la palabra con la cual se designaba a los dioses y también a las imágenes que los representaban. ${ }^{6}$ Llegamos así a un primer esclarecimiento. Al dar Lezama ese apellido al protagonista nos anticipa que no habrá de ser un personaje visto con pupila realista, un individuo que interese por los episodios de una vida privada que apenas servirán de hitos en la trayectoria de la novela. Por ello, quien lleva ese apellido es imagen, es mito. O sea, que José Cemí es para Lezama lo que Stephen Dedalus fue para Joyce.

La resolución de esta primera clave nos abre también el sentido del título. No obstante la grafía italianizada, Paradiso apenas tiene que ver con los treinta y tres últimos cantos de la Divina comedia. El paraíso de Lezama Lima es Cuba. Pero no sólo la Cuba de tierra, agua y sol que yace anclada en el Mar Caribe. Es además una Cuba vislumbrada a través de recuerdos que han sido alterados por una alucinante visión poética. $Y$ a lo que creo que alude el título, correspondiendo al nombre del protagonista, es al paraíso de los taínos. $Y$ hasta pudiera decirse que Lezama ha estado casi como clamando por que alguien notara el origen antillano del mito que se trasluce en el título. En respuesta a la pregunta: “ ¿Considera Ud. que en algún sentido puede ser determinante en su obra el que Ud. sea cubano?", declara como para señalar una pista:

\footnotetext{
4 La edición de 1970 todavía trae lo siguiente: "Tatno, na. adj. Dícese del individuo perteneciente a una de las tribus que habitaron, según unos, en la región del Alto Orinoco y según ottos en las Antillas. 2. Dialecto caribe que hablaban estas tribus y que todavia se conserva en el Noroeste del Brasil'. En efecto, los taínos emigraron a las Antillas desde Sur América, pero su idioma pertenece a la familia de lenguas arahuacas, no a las caribes. Las lenguas arahuacas se hablan todavía, no sólo en el interior del Brasil, sino también en las Guayanas y la Guajira.

5 Sobre la sobrevivencia de estos mitos en creencias religiosas véase " La Virgen del Cobre: historia, leyenda y simbolo sincrético", recogido en mi libro Certidumbre de América, 2da. ed., Madrid, Gredos, 1971, págs. 184214; sobre su presencia en la literatura, "Mitos taínos en las letras de Cuba, Santo Domingo y México", recogido en el mismo libro, págs. 59.76.

6 Para un estudio más amplio de dicha mitologia véase mi libro Mitología y artes prebispánicas de las Antillas, México, Editorial Siglo XXI, 1975.
} 
Como no puedo concebirme nada más que como cubano, no puedo afirmar que si hubiera nacido italiano hubiera escrito otra Divina comedia, pero sí puedo decir que como cubano he podido escribir un Paradiso. Otros vecinos, otros susurros, otros hilos relacionables entre la dama y el rosetón pitagórico, me han dado otras posibilidades y otra verificación. Entre nosotros paraíso es como naturaleza, no como símbolo o arquetipo. El hombre primitivo que habitó nuestras tierras es uno de los misterios humanos más cerca de lo angélico que hayan existido; fue, pudiéramos decir, la primera modalidad coral de lo que he llamado el genitor por la imagen. ${ }^{7}$

Si la pista es válida, Lezama está apuntando hacia Coaybay, 'casa y habitación de los ausentes', el misterioso valle donde de día reposaban los espíritus para regresar, al amparo de las sombras de la noche, a danzar sus corales areitos, a alimentarse de la dulce pulpa de las guayabas y a gozar del no menos dulce deleite de visitar en las hamacas a sus amantes dormidas. Con esa imagen paradisíaca de Cuba Lezama continúa una tradición que comienza con las páginas que Colón pergeña al describir la edénica belleza de la isla recién descubierta, se extiende a lo largo de la poesía cubana de todos los tiempos, y se afirma, polarizándose hacia la visión de los cubanos que deploran los males que sufre el país, en la novela de José Antonio Ramos que precisamente se titula Coaybay. ${ }^{8}$ Esa Cuba de añoranzas, de ternuras y de ensueños es, pues, la que alienta en esta novela que también va "a la recherche du temps perdu". Pero la Cuba de nuestro memorioso criollo no es la París de Proust. En lugar de las vanas preocupaciones de una nobleza venida a menos, en Paradiso afloran, como filtrándose por los resquicios del subconsciente colectivo, los ancestrales gozos del taíno que los cubanios llevamos dentro. Y por ello el destacado lugar que en la novela ocupan las fiestas musicales nocturnas, el deleitoso saboreo de las frutas y el notorio capítulo octavo que alcanza el vigor expresivo de un himno fálico.

Igual que Proust evoca las Crónicas de Jean Froissart para contrastar las guerras y aventuras de los nobles medievales con los deterioros que el tiempo ha efectuado en la aristocracia francesa, Lezama Lima recurre a las crónicas de Indias para reavivar recuerdos de nuestro pasado y con ellos enriquecer la suntuosidad de su mundo novelesco. ${ }^{9}$ En los cronistas de Indias halló los elementos míticos que se acaban de advertir, ${ }^{10}$ y a los cronistas

7 Eugenia Nieves, "'Entrevista con José Lezama Lima", A Arbol de Letras, número citado, pág. 21.

${ }^{8}$ La novela de José Antonio Ramos (1885-1946) se publicó en La Habana en 1927. De ella dice Max Henriquez Ureña en su Panorama bistórico de la literatura cubana, vol. 2, Puerto Rico, 1963, pág. 338: “En 1927 vio la luz Coaybay, suerte de fantasía política en un país imaginario, aunque por los elementos fonéticos del título se comprende que quiere aludir a Cuba"'. Por los elementos fonéticos, y más aún por las resonancias miticas.

${ }^{9}$ Lo ha declarado explícitamente en varias entrevistas. (Véase Recopilación de textos sobre José Lezama Lima. Selección y notas de Pedro Simón. La Habana, 1970, págs. 33 y 36). Se comprueba, además, mediante los informes que indico en la nota 7 .

${ }^{10}$ Los datos sobre estos mitos se hallan en algunas páginas de Colón, en el informe que por orden de Colón preparó fray Ramón Pané (y que aparece intercalado en la Vida del Almirante...por su bijo Fermando), en una de las cartas de Pedro Mártir de Angleria, incluida en sus Décadas del Nuevo Mundo, en la cual resume lo que le pareció de mayor interés en el opúsculo de Pané, y en dos largos pasajes de la Ápologética bistoria de lás Indias, er. los que Las Casas compendió el referido opúsculo. He reunido, confrontado y anotado esos documentos en la edición de Fray Ramón Pané, Relación acerca de las antigltedades de los indios, México, Editorial Siglo XXI, 1974. 
de Indias hemos de volver para explicar otras alusiones fundamentales de Paradiso. Por ejemplo, la que pudiera servirnos para abrir una senda de luz hasta el centro del oscuro pasaje en que se narran las orgías del millonario Elpidio Michelena en su finca matancera.

Este pasaje, el más hermético de toda la novela, es también uno de los más importantes para entenderla a fondo. Como tal vez se recuerde, ocurre en el capítulo tercero, en medio de las peripecias de la familia Olaya durante la emigración a Jacksonville. ${ }^{11}$ Mediante una evocación retrospectiva el autor nos lleva a Cuba y describe lo que en apariencia comienza como un inocente cuadro de costumbres: Andrés Olaya, huérfano y pobre, vive en casa del Sr. Michelena. En la cena en compañia de don Elpidio y su mujer, el criado chino que atiende a la mesa pasa tan de prisa las fuentes ante el joven que éste apenas alcanza a servirse. Retirados los señores, Olaya zamarrea al criado. Al ruido acude don Elpidio, lleva a Andrés a la sala, le pide que se una a él y a su esposa en las rogativas que hacen a la Virgen, y desde ese día comienza a beneficiarlo en los negocios. En una de las diligencias mercantiles Andrés va a Matanzas y se hospeda en un hotel. Para completar el marco al aludido pasaje, el autor agrega: "El joven de la carpeta con cínica indiscreción le empezó a hacer comentarios de las visitas anteriores de su señor, de las iluminaciones y juegos en una de sus fincas, y de la suerte, piel y cabellera de la mujer que daba uña en aquellos rasgueos y escrituras fiesteras" (pág. 65).

Lezama ha expresado en una entrevista que cuando se siente claro escribe prosa, y cuando se siente oscuro escribe poesía. ${ }^{12}$ Pues bien, hasta este momento la novela había fluído en una prosa que, en relación al estilo de Lezama, casi pudiera calificarse de transparente. Pero en el trozo a que me refiero hay un despliegue tal de insospechados neologismos, de fastuosas metáforas, de veladas alusiones, de sustituciones perifrásticas y de arcanos y mágicos simbolismos que nos sume en un alucinante mundo poético. Nos sume y, si nos descuidamos, también nos ahoga. Para no dejarnos hundir en ese mundo que el propio novelista concibe como semilíquido, en esta ocasión nos asiremos a la reiterada presencia de la palabra manati. No parece casual ni gratuito que en menos de siete páginas ese término se repita diez y ocho veces. Dada la destacada oralidad de Paradiso, resulta evidente que manatí es ante todo, como dice el propio José Cemí de otra voz, una palabra "oída y saboreada" (pág. 59). En efecto, manatí produce un halago melódico con esas ' $a$ 's abiertas que de pronto se agudizan en el chasquido oxitónico de la 'i', y tiene un extraño sabor que invita al paladeo de cada silaba. Pero en estos episodios es algo más: sirve de leitmotif que une los movimientos de lo que en verdad resulta una báquica sinfonía tropical. Ahora bien, si acudimos otra vez al Diccionario de la lengua española, nada hallamos en la definición del término manati que nos ilumine la ruta hacia su insólito simbolismo. Pero si leemos a los cronistas de Indias, pronto surge, clarísima, la explicación: la imagen del manatí entra en las crónicas envuelta en un halo de lo asombroso, lo ilusorio y lo fantástico. El iniciador de esa corriente fue el propio Cristóbal Colón. A1

\footnotetext{
11. El pasaje citado ocupa las páginas 65 a 72 en la edición de Buenos Aires, Ediciones de la Flor, 1968. Todas las demás citas se refieren a esta edición.

12 Informa Lezama: "Para llegar a mi novela, hubo necesidad de escribir mis ensayos y de escribir mis poemas. Yo dije varias veces que cuando me sentia claro escribía prosa y cuando me sentía oscuro escribía poesía'. (En Recopilación de textos sobre J.L.L., pág. 25).
} 
descubrir una familia de manatíes junto a la costa de la Española, filtra la imagen americana a través de un mito europeo, asienta en su Diario que "vido tres sirenas, que salieron bien alto de la mar", y concluye este primer modelo de lo real maravilloso en nuestras letras agregando, creo que un poco mohino: "pero no eran tan hermosas como las pintan, que en alguna manera tenían forma de hombres en la cara" ${ }^{13}$ Inmerso en la atmósfera creada por Colón, su compatriota Pedro Mártir de Anglería poco después relata un "inaudito prodigio" cuyo protagonista es un manatí. A este manatí lo describe, como si lo extrajera de un fabuloso bestiario medieval, como un "monstruo desconocido en nuestros mares", "un cuadrúpedo en forma de tortuga, pero protegido de escamas y no de concha", "de lomo plano", que "vive en el agua y en la tierra", y "es manso, perezoso y sociable como el elefante y el delfín". Los manatíes que aparecen en las referidas páginas de Paradiso son, por consiguiente, metáforas que aluden a las "sociables" sirenas que acompañan a Michelena en sus orgías. Descifrado el código poético, las frases "desperezaba su lomo de algas", "las pequeñas escamas que le regalaba el sudor caricioso", " "yerbazales de agua", "aceitado monstruo" y otras que antes evocaban una realidad apenas comprendida, ahora cobran su plena lucidez y adquieren toda su potencialidad expresiva.

Una vez abierta la trocha de luz hacia la casona campestre, alli encontramos a dos sirenas-manatíes. Michelena estaba "dándole vuelta a la champanizada vírgula de la copa', en compañía de una 'irreconocible Isolda", cuando se entreabrió la puerta y apareció la otra, que "parecía ocultar el bultejo que se aprestaba a defender con llanto y ronda de entreolas". Echada violentamente de la casa, batida por el "cordonazo" (el "cordonazo de San Francisco" es un viento huracanado), baja al jardin y se dirige a un sirviente que "hacía señas y sentencias al manatí apaleado para que no se acercase". Este sirviente, a quien reconocemos como el mismo de la cena anterior por las frases perifrásticas con que el autor lo mienta ("Apresurado Lento", "Pasa Fuente Veloz", "Buñuelo de Oro", "Bandeja Saltamontes"), al principio contempla impávido las turbulentas escenas que siguen. Esas escenas cobran un delirante tono fantasmal, en que el tiempo se enturbia y se deslíe, y culminan en una pavorosa danza de la muerte. Terminada la danza quedan, vibrando en el aire espeso de la noche, "la carne izada del manatí" 'y Buñuelo de Oro, que para llevar la noticia a la casona, " con el puño crispado aún seguía golpeando a la puerta hasta que se hundió en la madera ablandada por la lluvia".

No es mi propósito esclarecer todas las alusiones que aparecen en esta elegía al manatí muerto. Pero queda una que debo comentar, primero, porque pudiera prestarse a nuevas confusiones, y luego, porque ilumina uno de los procesos fundamentales del sistema poético de Lezama. Habiendo asentado que Pasa Fuente Veloz hizo "señas y sentencias al manatí apaleado para que no se acercase", bruscamente, sin transición alguna, escribe: "En el bosque correspondía al costado izquierdo, el árbol de Hanga Songa, que proyecta sombras hacia arriba" (págs. 67-68). No sería extraño que algún imaginativo filólogo, para explicar el sentido de esta última oración, descubra resonancias yorubas en el tamborileo silábico del nombre del árbol. Y si además conoce la geografía de Cuba, tal vez

\footnotetext{
${ }^{13}$ Se encontrarán las referencias a éste y los siguientes informes en mi artículo "Manatí el testimonio de los cronistas y el problema de su etimologia", Boletin del Museo del Hombre Dominicano, Santo Domingo, 2, octubre de 1972, págs. 33-38.
} 
complete su explicación recordándonos que en la provincia de Oriente hay por lo menos dos topónimos de raíz africana: el de un municipio llamado Songo y el de un barrio de homofonía aún más cercana a Hanga Songa: Hongolosongo. Pero esa demostración haría sonreír a Lezama, pues no es cruzando el Atlántico, sino el Pacífico, que se da con el árbol que "proyecta sombras hacia arriba". Y conste que no creo que Lezama haya tenido la menor intención de armarle una trampa al desorientado viajero de los océanos lexicográficos. Aunque en apariencia no hay relación lógica entre ambas oraciones, sí la hay en la mente del autor: imantado el recuerdo de extensas lecturas por la presencia de Buñuelo de Oro, le confiere un árbol genealógico. Ese árbol genealógico es el que, proyectando sus sombras hacia el pasado, las remonta a dos dinastías chinas: la de los Han y la de los Song. El sistema poético de Lezama ha funcionado, pues, como una cubeta de datos culturales en suspensión que en un determinado momento cristalizan en fastuosas metáforas.

Volvamos a la otra sirena, la que al principio del episodio Lezama llamó “irreconocible Isolda" '. Al pasar el relato del manatí-izado al manatí-Isolda, de pronto amainan las turbulencias poéticas, se apaciguan las palabras y se aquieta el estilo. Lo que realmente sucede es que se ha pasado de un plano elegíaco a otro de evocaciones históricas. La infiel Isolda de la leyenda medieval aquí es una sevillana ("del sur hispalense"), que llega a Cuba en una época definida ("La Habana del General Serrano"), en compañía de un músico catalán, Joan Albayat. Albayat recala en Matanzas y entra a formar parte del cuarteto que ameniza las fiestas de Michelena. En el cuarteto figura también Luis Mendil, "un mestizo en octavo". Isolda, haciendo buena la alusión implícita en su nombre, tiene inclinaciones poliándricas bastante parecidas, dicho sea de paso, a las de Molly Bloom en Ulysses: en una especie de billar a tres bandas juega con Albayat, juega con Michelena y juega con Mendil. A hora bien, de estos personajes es sólo Mendil quien atrae hacia sí las alusiones históricas que le confieren un especial interés literario. "Su bisabuelo", apunta Lezama, "había rizado a Sir George Pocock"' (pág. 69). O sea, que había sido peluquero del almirante inglés cuyas tropas ocuparon La Habana desde agosto de 1762 hasta julio de 1763. Isolda se va a vivir con Mendil, " "pero el octavón tedioso le dejaba sus escapadas, y las aprovechaba para repasarse a su gusto una Misa de la Caridad de Esteban de Salas' (pág. 70). Esteban Salas (1725-1803) es el primer compositor y músico importante que tuvo Cuba; olvidado después de su muerte, sus obras fueron redescubiertas por el mejor historiador de la música cubana, quien no es otro sino Alejo Carpentier. ${ }^{14}$ Hasta el color de Mendil tiene importancia en esta evocación: primero le llama "mestizo en octavo" y luego "el octavón". Lezama, jugando ingeniosamente con voces que a la vez sugieren lo musical y lo racial, por analogía con "ochavón", acuña el cultismo "octavón"'. Pero no lo hace únicamente por deleite verbal. La mención de fechas definidas, el oficio del bisabuelo, las relaciones con una española, y el propio ambiente matancero, llevan al lector cubano a configurar una imagen que recuerda al desdichado poeta que Max Henríquez Ureña describe como "hijo de una bailarina burgalesa...y de un cuarterón que era peluquero", '15 es decir, Gabriel de la Concepción Valdés, "Plácido"' (1809-1844). El

\footnotetext{
14 Alejo Carpentier, La música en Cuba, México, Fondo de Cultura Económica, 1946, págs. 59-71.

15 Max Henriquez Ureña, Panorama bistórico de la literatura cubana, tomo I, Puerto Rico, Ediciones Mirador, 1963 , pág. 166.
} 
resultado es como si Lezama, mediante sutiles alteraciones de la realidad histórica, nos diera un Plácido a quien le alargara la vida, alevosamente tronchada por las autoridades coloniales, para evocarlo con oficio de poeta músico. Logra así, igual que hicieron Proust y Joyce, trasmutar e incorporar a su novela elementos de la mejor tradición cultural de su patria.

Sería grato empeño seguir comentando otros elementos, implícitos y explícitos, que profundizan y amplían lo cubano en Paradiso. Me gustaria, por ejemplo, para subrayar el tema de las frutas, comenzar por las míticas guayabas de que se alimentaban los espíritus de los taínos muertos en sus nocturnas escapadas de Coaybay; continuar con las "frutas de muy maravilloso sabor" que imaginativamente paladeaba el hiperbólico Colón; elogiar el colorido de aquel bodegón verbal, compuesto de

$$
\begin{aligned}
& \text { guanábanas, gegiras y caimitos, } \\
& \text { mameyes, piñas, tunas y aguacates, } \\
& \text { plátanos y mamones y tomates, }
\end{aligned}
$$

que el acriollado y goloso Silvestre de Balboa nos dejó en su Espejo de paciencia; puntualizar la devoción patriótica con que Zequeira le inventa un mítico origen griego a la piña, y manifestar el incipiente separatismo con que Rubalcava inicia, en palabras de Lezama al aludirlo en la novela, "el debate de la supremacía entre frutas españolas y cubanas" (pág. 27). De ese modo quedaría expuesta la recia raíz de las frutas que aparecen en Paradiso y se entendería mejor el júbilo con que se incorporan esas descripciones en algunas de las páginas más memorables de la novela.

Ahora bien, para no exceder los breves límites de este ensayo, me ocuparé sólo de un aspecto más, el cual no puede ser soslayado pese a los riesgos que su estudio conlleva. Es el siguiente: ¿hasta qué punto resulta la hazaña verbal de Lezama culminación de tendencias constantes en las letras y el habla cubanas? Puesto que tal hazaña es, en última instancia, un logro muy personal, tal vez debiera de limitarme a calificarla, como hacen varios críticos, de "tropicalismo", o como hace el propio Lezama, de "barroco fervoroso". ${ }^{16}$ Lo malo es que esos términos carecen de contornos semánticos precisos. "Tropicalismo", en el caso que nos ocupa, tiene un tono tan ambiguo que no siempre se sabe si es elogio o censura. Además, si por tropicalismo se entiende una causa telúrica que lleva a la oralidad exaltada o a la ampulosidad desmedida, ¿no son oriundos del trópico escritores de prosa tan ceñida y firme como José de la Luz Caballero, Enrique José Varona y Pedro Henríquez Ureña? Y si, por analogía con una imagen parcial de la vegetación de los trópicos, se le quiere dar la connotación de abigarrado crecimiento o, peor aún, de excesiva hojarasca, ¿no se da esa hojarasca, que es producto de la incultura y no del clima, en escritores de otras zonas? Ese término, por consiguiente, debiera eliminarse de la crítica literaria no sólo por su ambigüiedad, sino también por constituir lo que llamaré una falacia geográfica: querer clasificar un estilo por grados de latitud norte o sur y no por cualidades inherentes al quehacer literario. En cuanto al término "barroco", si bien se refiere a un estilo artístico definido, a veces también se presta a confusiones cuando deja de connotar las características que predominan en un determinado período de la historia de las artes para aplicarse a

il Recopilación de textos..., pág. 27. 
cualidades que aisladamente aparecen a lo largo de épocas muy diferentes. Para la tarea que me propongo no basta, pues, con encasillar la hazaña de Lezama bajo ambiguos rótulos. De ahí que prefiera intentar la verificación de significativas afinidades con escritores, de honda impronta en la tradición antillana, a los cuales Lezama conoce tan a fondo que constituyen parte del acervo que todo autor escoge, asimila e incorpora a su particular estilo. $\mathrm{Y}$ he de empezar, otra vez, por Colón y los cronistas de Indias. El testimonio de Lezama a este respecto no puede ser ni más claro ni más sincero. Con motivo de la nueva novela hispanoamericana atestigua: "En esa novela hay algo del deslumbramiento ante el nuevo paisaje que caracterizó a aquellos grandes escritores que fueron los cronistas de Indias, que nos regalaron, con las nuevas fabulaciones, nuevos sentidos". ${ }^{17}$ Y refiriéndose al Descubridor: "En tres momentos está sintetizada toda la historia de Cuba. El primero consta en el diario de navegación de Cristóbal Colón: allí se lee que el Almirante, sobrecogido por la espléndida cabellera de una india, exclama: 'Semejante a seda de caballo'!... Todos nosotros hemos heredado los atributos de esa cabellera: la tersura de la seda, la indómita valentía de los caballos". ${ }^{18}$

Glosando estas declaraciones cabe inferir que Lezama aprendió en Colón y los cronistas a concebir un paisaje subjetivo, visto desde la raíz de la poesía, y a inventar nuevas fabulaciones y sentidos, como los que hemos observado en el episodio de las sirenasmanatíes. Que de Colón y los cronistas aprendió la indómita valentia ante el lenguaje, para obligarlo a extenderse hasta lograr nuevas posibilidades expresivas. Que de ellos aprendió el uso de indigenismos antillanos, de los "oidos y saboreados", para conferir a su prosa fulguraciones de cocuyos, o para lanzar desde ellos amplificaciones como éstas: "corría como tironeado por nubes de buracán (pág. 26)...un rosado plúmbeo que retrocedía ante el siena criollo, pareciendo como si su piel se agrietase con un ruido de frotadas bijas (pág. 45)...el ala del yareytembloroso como hoja de algodón'” (pág. 79), y otras que me eximo de citar. Y que aprendió, en fin, el arte de evocar realidades innominadas con circunloquios que recuerdan aquel en que Colón llama a unas yaguas extendidas en el suelo "un estrado de camisas de palmas". ${ }^{19}$

Hay algo más, esta vez en relación a Las Casas, que a lo mejor resulta demasiado tenue para resistir el peso de una comprobación categórica. Me refiero, en primer lugar, a esa desgreñada sintaxis de ambos, que impelida por una incoercible vitalidad verbalizadora apenas deja tiempo a la pluma para atrapar con sus rasgueos lo que el pensamiento dicta. Y me refiero a otra coincidencia, tal vez de mayor importancia. La Apologética historia de las Indias es también una summa, summa que se apropia del extenso caudal erudito de su época para proyectar una imagen subjetiva del hombre americano. Las autoridades que acopia Las Casas y las alusiones, referencias y citas que despliega Lezama tienen, por consiguiente, un común origen y acaso un común destino: ganarse al lector deslumbrándolo con persuasiones librescas.

En la población cubana siempre ha habido, además, los que gustan, por una parte, de frases perifrásticas, adjetivaciones altisonantes y comparaciones grandilocuentes, y por otra

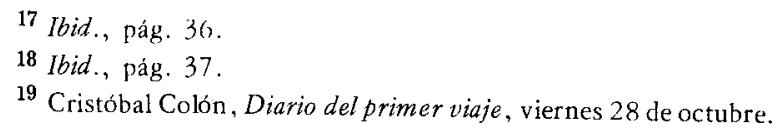


parte, los que se deleitan en giros alambicados y sustituciones agudas. Ya en el siglo XVI los escribanos habaneros se referían a Cuba, para mayor pompa, como la "isla Fernandina de las Indias del mar Oceano". ${ }^{20}$ No sabría decir cómo se extendió ese impulso amplificador a otros estratos de la sociedad cubana. Ni tampoco cuándo se originó, por efecto contrario, la alteración del nombre de la isla mediante un diminutivo para crear una imagen subjetiva y recoleta: Cubita, Cubita Bella. Lo cierto es que el propio Lezama ha comentado algunos extraordinarios ejemplos de sutilezas oídas en boca del pueblo en su ensayo "Verba criolla" ${ }^{21}$ E igualmente cierto es que ambas tendencias, pasando de lo refinado a lo cursi, con frecuencia aparecen en oradores políticos, en cronistas sociales y hasta en pintorescos personajes locales cuyo engolamiento acaba sirviendo de blanco a ese humorismo disolvente que los cubanos llamamos "choteo".

Hay, pues, de todo en esa tradición que en Paradiso se depura y eleva a la altura del arte. $\mathrm{Y}$ lo que desearía destacar es que, reunidos aquellos diversos elementos, y trasmutados e incorporados en su obra, Lezama ha conseguido universalizar aspectos de la mitología, la historia, las letras, las costumbres y el habla cubanas, y darnos en Paradiso lo que hoy nos parece uno de los mayores logros de la nueva novela hispanoamericana.

Yale University

JOSE JUAN ARROM

${ }^{20}$ Sobre ésta y otras designaciones que se han dado a Cuba véase mi estudio El nombrede Cuba: sus vicisitudes y su primitivo significado, La Habana, [Academia Cubana de la Lengua], 1964.

21 José Lezama Lima, Tratados en La Habana, Santa Clara, Universidad Central de Las Villas, 1958, págs. 181 184. 
